

\section{DISCLAIMER}

This report was prepared as an account of work sponsored by an agency of the United States Government. Neither the United States Government nor any agency thereof, nor any of their employees, makes any warranty, express or implied, or assumes any legal liability or responsibility for the accuracy, completeness, or usefulness of any information, apparatus, product, or process disclosed, or represents that its use would not infringe privately owned rights. Reference herein to any specific commercial product, process, or service by trade name, trademark, manufacturer, or otherwise, does not necessarily constitute or imply its endorsement, recommendation, or favoring by the United States Government or any agency thereof. The views and opinions of authors expressed herein do not necessarily state or reflect those of the United States Government or any agency thereof.

Printed in the United States of America Available from

National Technical Information Service

U.S. Department of Commerce

5285 Port Royal Road

Springfield, VA 22161

NTIS price codes

Printed copy: A04

Microfiche copy: A01 


\section{DISCLAIMER}

This report was prepared as an account of work sponsored by an agency of the United States Government. Neither the United States Government nor any agency Thereof, nor any of their employees, makes any warranty, express or implied, or assumes any legal liability or responsibility for the accuracy, completeness, or usefulness of any information, apparatus, product, or process disclosed, or represents that its use would not infringe privately owned rights. Reference herein to any specific commercial product, process, or service by trade name, trademark, manufacturer, or otherwise does not necessarily constitute or imply its endorsement, recommendation, or favoring by the United States Government or any agency thereof. The views and opinions of authors expressed herein do not necessarily state or reflect those of the United States Government or any agency thereof. 


\section{DISCLAIMER}

Portions of this document may be illegible in electronic image products. Images are produced from the best available original document. 
GA-A15314

UC.77

\title{
LICENSING TOPICAL REPORT: APPLICATION OF PROBABILISTIC RISK ASSESSMENT IN THE SELECTION OF DESIGN BASIS ACCIDENTS
}

\author{
by \\ W. J. HOUGHTON
}

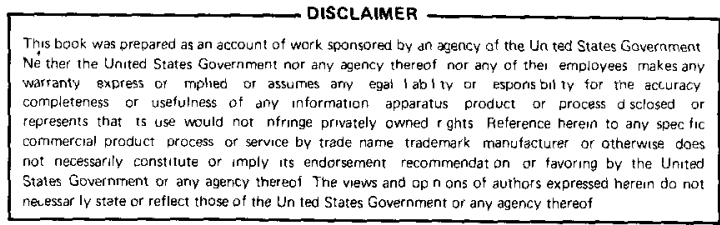

Prepared under

Contract DE-AT03-76ET35300 for the San Francisco Operations Office

Department of Energy

GENERAL ATOMIC PROJECT 6400

DATE PUBLISHED: JUNE 1980

\section{GENERAL ATOMIC COMPANY}




\section{FOREWORD}

This Licensing Topical Report has been prepared for submittal to the Office of Nuclear Reactor Regulation for endorsement that the process it describes is acceptable for use in the selection of Design Basis Accidents to be analyzed in Chapter 15 of Safety Analysis Reports for high-temperature gas-cooled reactors (HTGRs).

The subject matter of this report has been selected for review as one of the issues which bear on the licensing of HTGRs. Review prior to an application for a construction permit would expedite the licensing process and provide a basis for licensing HTGRs on their own merit. 
ABSTRACT

A probabilistic risk assessment (PRA) approach is proposed to be used to scrutinize selection of accident sequences. The PRA methodology applied is that of the Accident Initiation and Progression Analysis (AIPA) Program, as exemplified in Section 4 of GA-A15000, "HTGR Accident Initiation and Progression Analysis Status Report, Phase II Risk Assessment." This method considers accident sequences comprised of accident initiating events, single and multiple failures as well as common cause failures.

A technique is described in this Licensing Topical Report to identify candidates for Design Basis Accidents (DBAs) utilizing the risk assessment results. As a part of this technique, it is proposed that events with frequencies below a specified limit would not be candidates. The use of the methodology described herein is supplementary to the traditional, deterministic approach and may result, in some cases, in the selection of multiple failure sequences as DBAs; it may also provide a basis for not considering some traditionally postulated events as being DBAs.

A process is then described for selecting a list of DBAs based on the candidates from PRA as supplementary to knowledge and judgments from past licensing practice. These DBAs would be the events considered in Chapter 15 of Safety Analysis Reports of high-temperature gas-cooled reactors (HTCRs). This approach is new to the customary licensing procedures and is provided to expedite the licensing process when an application is made and to provide a basis for licensing HTGRs on their own merit. 
CONTENTS

FOREWORD . . . . . . . . . . . . . . . . . . . . . iii

ABSTRACT . • . . . . . . . . . . . . . . . . . . . . . V v

1. PURPOSE AND INTRODUCTION . . . . . . . . . . . . . . . . . 1

1.1. Purpose of This Licensing Topical Report . . . . . . . 1

1.2. Introduction . . . . . . . . . . . . . . . . . 1

2. SUMMARY . . . . . . . . . . . . . . . . . . . . 3

3. PRA METHODOLOGY AND ITS APPLICATION . . . . . . . . . . . 8

3.1. PRA Methodology. . . . . . . . . . . . . 8

3.1.1. Initiating Event Selection . . . . . . . . . 10

3.1.2. Event Tree Construction. . . . . . . . . . . . 10

3.1.3. Sequence Frequency Quantification. . . . . . . 11

3.1.4. Sequence Consequence Quantification. . . . . . 16

3.1.5. Presentation of Results. . . . . . . . . . 17

3.2. PRA as a Supplementary Procedure . . . . . . . . 17

3.3. PRA Historical Background. . . . . . . . . . . 18

3.4. NRC Applications of PRA . . . . . . . . . . . . . 20

4. INTERPRETIVE TECHNIQUE FOR SELECTION OF DBA CANDIDATES . • . . 22

4.1. Overview . . . . . . . . . . . . . . . 22

4.2. Frequency Limit Line . . . . . . . . . . . . . 24

4.3. Events Above the Frequency Limit Line . . . . . . . . . 27

4.4. Events Below the Frequency Limit Line . . . . . . . . 30

5. EVALUATION OF DBA CANDIDATES . . . . . . . . . . . . . . 31

5.1. Historical Perspective . . . . . . . . . . . . 31

5.2. PRA Interpretations . . . . . . . . . . . . . 31

5.3. Application to Chapter 15 of SARs . . . . . . . . 32

REFERENCES . . . . . . . . . . . . . . . . . . . . . . 34

APPENDIX A: DERIVATION OF CHARACTERISTIC FREQUENCY AND

CONSEQUENCES WHICH ACCOUNT FOR UNCERTAINTIES. • • • • 36

APPENDIX B: DERIVATION OF REPRESENTATIVE NUMERICAL VALUES

ASSOCIATED WITH AVERAGE FREQUENCY . . . . . . . . • 47 


\section{FIGURES}

1. Steps in the selection of design basis accidents for Chapter 15 of Safety Analysis Reports . . . . . . . . . . . . . 4

2. Example of comparison of accidents . . . . . . . . . . 6

3. Major elements of the AIPA risk analysis methodology . . . . 9

4. Example event tree.................. 12

5. Fault tree for equipment train for recirculation cleanup system . . . . . . . . . . . . . . . . . . 14

6. Graphical display of interpretive technique . . . . . . . . 23 


\section{PURPOSE AND INTRODUCTION}

\subsection{PURPOSE OF THIS LICENSING TOPICAL REPORT}

This Licensing Topical Report has been prepared for submittal to the Office of Nuclear Reactor Regulation for endorsement that the process it describes is acceptable for use in the selection of Design Basis Accidents (DBAs) to be analyzed in Chapter 15 of Safety Analysis Reports (SARs) for high-temperature gas-cooled reactors (HTGRs).

\subsection{INTRODUCTION}

Design Basis Accidents for Chapter 15 of SARs have been chosen in the past in ways that have evolved over a long period of time. The use of probabilistic risk assessment (PRA) in regulatory decision making will allow the introduction of supplementary information into the DBA selection process. This information would include the specification of event sequences as DBAs going beyond the traditional single failure criterion. These would be considered for inclusion in Chapter 15 of the SAR along with some other accident sequences previously evaluated for HTGRs. Recognition and use of PRA is expected to improve knowledge of the relations of accident sequences to one another and their relative importance, and to assist in making the licensing of nuclear reactors more systematic. A method is needed to interpret and judge the results of probabilistic risk assessments so as to select DBAs. This report describes such a method.

The supporting probabilistic risk assessment methodology is that applied in the Accident Initiation and Progression Analysis (AIPA) study as exemplified in Section 4 of GA-A15000, "HTGR Accident Initiation and 
Progression Analysis Status Report, Phase II Risk Assessment" (Ref. 1). Pertinent aspects of this methodology are summarized in Section 3.1 of this report.

The actual application of this method is proposed to be the subject of a separate future Licensing Topical Report which will provide a list of DBAs for a specific HTGR plant. 


\section{SUMMARY}

The proposed overall process for selection of design basis accidents is diagrammed in Fig. 1. The numbered boxes in Fig. 1 are referred to and further discussed in the following text. The probabilistic risk assessment analyses, in box 1, yield descriptions of many power plant accidents which are characterized by values of frequencies and consequences (box 2). This collection of characteristics must be interpreted in box 3 to determine which accidents should become candidates (box 4) to be DBAs. Knowledge of the choices and analyses for accidents in the past (box 5) is needed in the process of selecting the DBAs (box 6) from among the DBA candidates. This process provides a list of DBAs for use in Chapter 15 of SARs (box 7).

This Licensing Topical Report (LTR) covers the topics in the central dashed rectangle on the figure. A future LTR is proposed which will apply these techniques and processes to a power plant and thereby provide the specific information shown in the dashed rectangle on the right of the figure.

Each step in the process will now be discussed with emphasis on the interpretive technique in box 3 .

\section{PRA Analyses (Box 1)}

The probabilistic risk assessment of the power plant identifies accidents for study in a systematic way. It uses fault trees and event trees to achieve this. The frequencies, i.e., events per reactor-year, and the consequences, such as radiological dose in rem, are calculated for each accident. The calculations are realistic (not conservatively biased) to show the true importance of each parameter in the analysis, but uncertainties are also analyzed. 


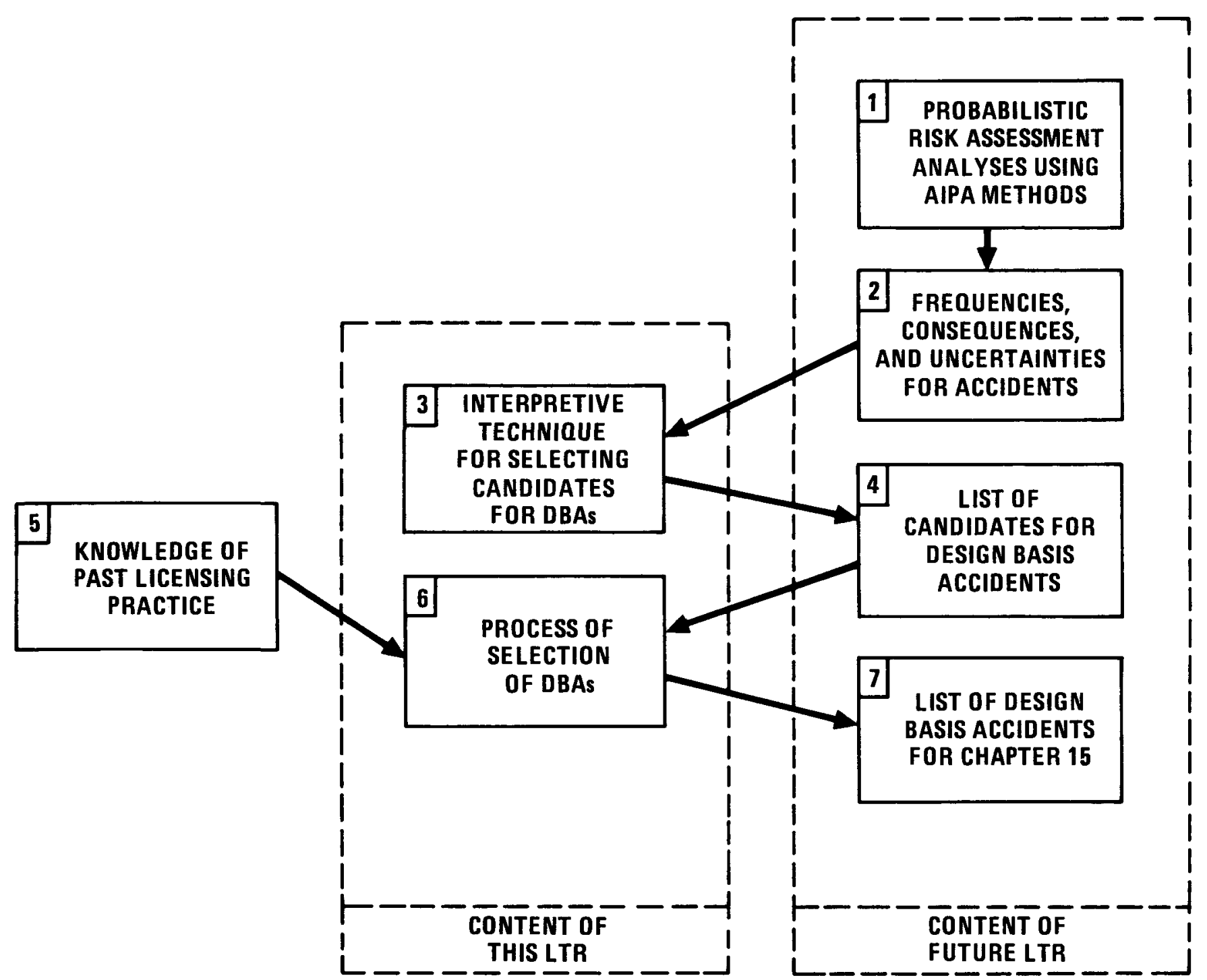

Fig. 1. Steps in the selection of design basis accidents for Chapter 15 of Safety Analysis Reports 


\section{Results of PRA Analyses (Box 2)}

Hundreds of accident sequences are often derived which cover a very wide range of frequencies and consequences which have broad spectrums of uncertainties.

\section{Interpretive Technique (Box 3)}

It is therefore necessary to interpret this mass of data to determine which accidents should be candidates for DBAs. The technique can be described by use of a plot as in Fig. 2, where an accident is shown as a point based on its mean frequency and mean consequence. The derivation for the use of means is given in Appendix A. The purpose of using means is to properly account for uncertainties when comparing one accident with another. Further development in the future might allow interpretation in terms of confidence level to be related to quantitative safety goa1s.

An accident such as plotted at point $A$ in Fig. 2 is a better candidate to be a DBA than is the accident at $B$ because $A$ is more likely, even though the two have comparable doses. Accident $\mathrm{C}$ is also a better candidate than $B$ because $C$ has a higher dose even though its likelihood is comparable to that of $B$.

The frequency limit line is shown at the bottom of this plot. Below this frequency limit, events should not be chosen to be DBA candidates. The value of the limit line is proposed to be a mean frequency of $2 \times 10^{-4}$ per reactor-year as derived in Section 4.2.

\section{Candidates for DBAs (Box 4)}

By examining a diagram showing the results, in terms of probabilities and consequences, of many accidents analyzed for a power plant, and 


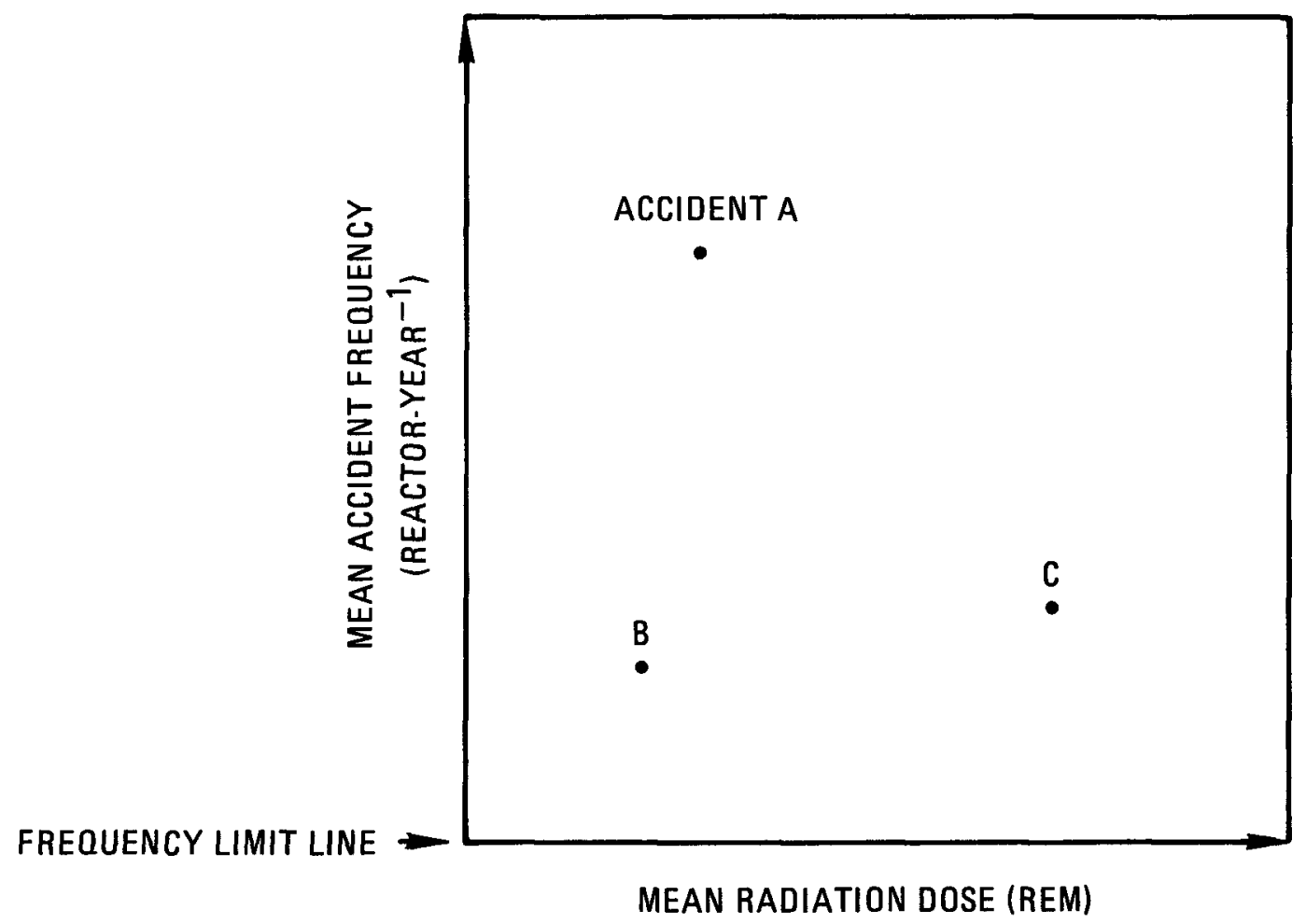

Fig. 2. Example of comparison of accidents 
studying the logic trees showing the interrelationships of accident sequences, a list of candidates for DBAs can be compiled that will be evaluated in Box 6 along with historical design basis accidents.

\section{Past Licensing Practice (Box 5)}

In the past, 1icensing experience for HTGRs has produced a set of DBAs that provide a reference base, e.g., the accidents analyzed in Chapter 15 of the PSAR for the proposed Fulton Generating Station. These design basis accidents will be scrutinized as a starting point in selecting an appropriate set of DBAs.

\section{Selection Process (Box 6)}

The list of DBA candidates from the probabilistic risk assessment considerations would be examined in the light of knowledge from past licensing practice. The purpose is to provide insights and crosschecks regarding the appropriateness of retaining historical accidents that may be excludable under the PRA selection criterion.

\section{List of DBAs (Box 7)}

In planning Chapter 15 for an SAR, the methodology of the preceding six steps would be applied to generate the list of DBAs to be analyzed.

The application of this approach will assist in making the licensing decisions more systematic and will thereby expedite and stabilize the licensing process in the long term. It will provide the benefits of more appropriate accident sequence selection and thereby improve safety. 


\section{PRA METHODOLOGY AND ITS APPLICATION}

\subsection{PRA METHODOLOGY}

The methodology of probabilistic risk assessment has undergone major development in the past few years. PRA has some characteristics that make it valuable in the licensing process. Many decisions made in licensing a nuclear power plant depend on judgments about whether a specific accident sequence is likely and about what the radiological doses, or consequences, of an accident would be. The PRA methodology is used to study accident sequences, and it yields the values for frequency and consequence for each sequence studied, including the uncertainties of those values. In addition, one of the significant benefits of the method is that it is systematic and encompassing and that it can be displayed so that the logic of the analysis can be examined.

PRA methodology is not codified. However, there are groups that have done assessments and have published reports containing their particular version of the methodology. The AIPA study group has done this (Refs. 1 and 2). The methodology developed therein, and utilized in Section 4 of Ref. 1 , is the specific PRA methodology adopted for use in conjunction with this report.

The AIPA methodology is displayed in Fig. 3 (adapted from Ref. 1). The main thread of the analysis is shown by the rectangular boxes and broader arrows. At the start, initiating events are selected on as broad and rational a basis as possible. Event trees are constructed that form the basis for identifying various accident sequences that could result from the initiating events. The frequency of occurrence of each sequence in an event tree is obtained by using mathematical logic to relate the events in 


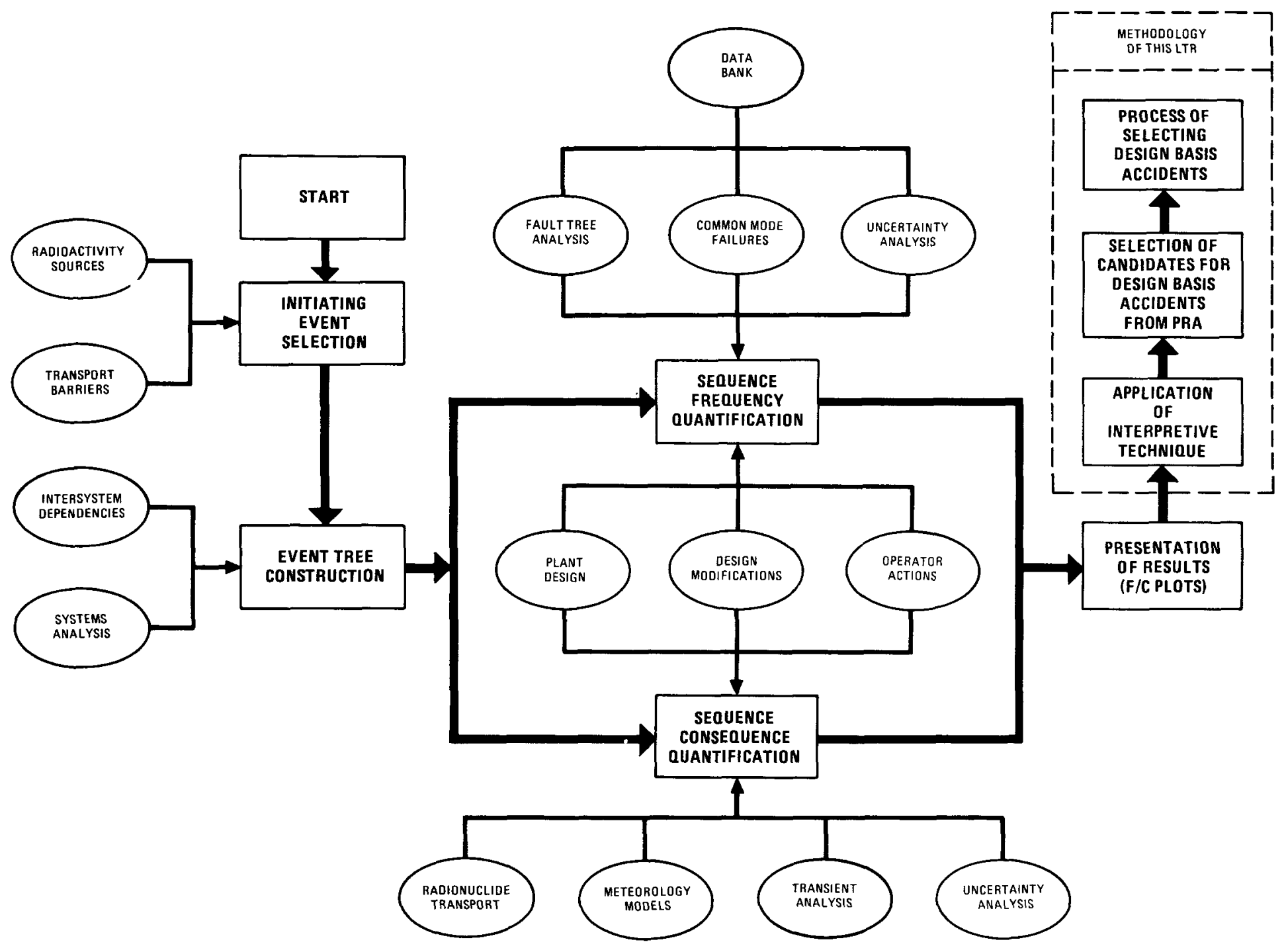

Fig. 3. Major elements of the AIPA risk analysis methodology 
question to more basic events that are quantified in terms of reliability experience data with similar systems and components. The consequences of the accident sequences are estimated in terms of effect on the health and safety of the public, such as radiological dose in rem. The results are subsequently presented in various ways, such as the plot of frequency vs consequence which is adopted in this report. The results will be used in the selection of design basis accidents.

\subsubsection{Initiating Event Selection}

Figure 3 will now be reexamined in more detail. The first step is to identify the initiating events that have the potential for the release of radionuclides to the environment. This is accomplished by identifying all sources of radionuclides in the HTGR and the physical barriers that normally prevent release. Anomalous events are identified that can trigger plant responses that could lead to breaches of these transport barriers and resulting radionuclide transport to the environment. Each such event is termed an

"initiating event" since it represents the starting point for event sequences in event trees that could lead to radionuclide release.

\subsubsection{Event Tree Construction}

An event tree can be constructed after an initiating event has been selected. The event tree will show the sequences of events that may occur following the initiating event. It provides for the possibility that some events may or may not occur, and the likelihood of their occurrence will be described by probabilities. In order to anticipate the possible sequences, one must understand the results of systems analysis which shows the response of the power plant to disturbances. A number of systems will be involved in many sequences, and intersystem dependencies must be accounted for in the event tree; for example, the loss of both off-site power and the main turbogenerator early in the sequence of an event tree will cause the shutdown of main loop cooling. 
The construction of an event tree can be begun by identifying the most likely progression of events to follow the initiating event. In a very simple example, the initiating event could be followed by a corrective action, thereby terminating the accident sequence. This is illustrated by sequence $A$, or branch $A$, in Fig. 4. Additional sequences are developed by considering the possibility that the events in the first sequence do not occur. If the corrective action, event 2 of Fig. 4, did not occur, there could be backup equipment which could respond to the accident as event 3 . The failure of the backup equipment to respond is also accounted for in the tree with an additional branch. A more complete description of how to construct an event tree is given in Section 3 in Volume II of Ref. 2 .

\subsubsection{Sequence Frequency Quantification}

The sequence frequency quantification, seen in Fig. 3, is done for the sequences in the event tree. The plant design and operator actions are included as are any design modifications which result from safety studies. To calculate the probabilities of the sequences, one employs fault tree analysis incorporating common mode failures. Techniques of uncertainty analysis are also employed, and many types of probabilistic data must be fed into the analysis from a data bank.

Each branch leaving a node in an event tree needs to have its probability determined in order to arrive at the frequency for each branch. For example, for Fig. 4, the sequence frequency corresponding to branch $\mathrm{C}$, designated $F(C)$, can be expressed as

$$
F(C)=F(1) \cdot P(\overline{2} \mid 1) \cdot P(\overline{3} \mid \overline{2}, 1),
$$




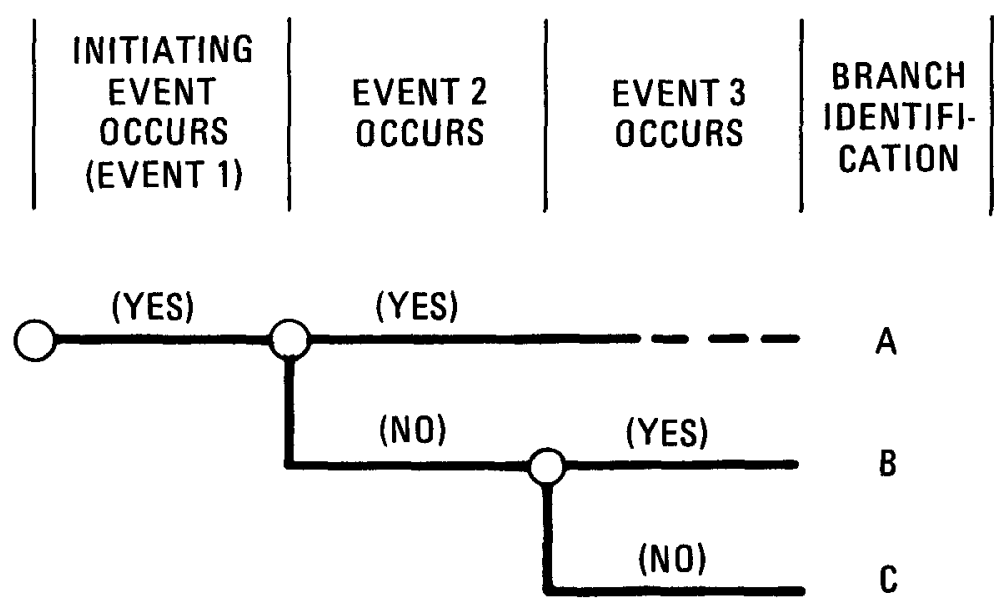

Fig. 4. Example event tree 
where

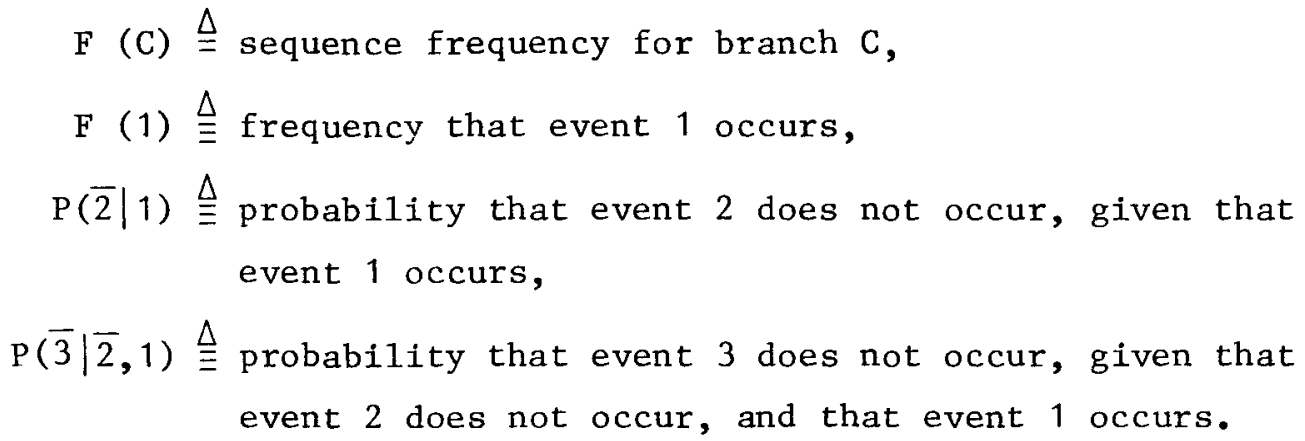

Each of the two terms on the right side of Eq. 1 is termed a branch point probability since it is associated with a branching point on the event tree. Note that each branch point probability depends on the outcome of branch points preceding it in the sequence.

The branch point probabilities are computed with fault trees. A branch point event is typically the occurrence of adequate operation of a system or failure of that system. A fault tree analyzes failure of a system by displaying the failures of the components of the system and their logical inter-relationships which lead to system failure. This result is also easily used to obtain the probability of system success.

A typical fault tree is shown in Fig. 5. This sample tree is for an equipment train for a containment recirculation cleanup system. The tree can be used to calculate the probability that equipment train number 1 fails at a time and under conditions specified by the branch point in the event tree where the answer will be used. The logic gate known as an "OR" gate is shown as G-6. It means that the equipment train will fail if there is no electric power or if there is failure of the circulation fans or if one of the three other indicated events $\left(x_{1}, x_{2}\right.$, and $\left.x_{5}\right)$ occurs. However, circulation fan failure causing equipment train failure can only occur if both fan A and fan B fail; this is indicated by the logical "AND" gate, which is shown below the fan-failure rectangle. The probabilities chosen as input to such a tree of course have to be consistent with the accident conditions found at that point in the event tree. 


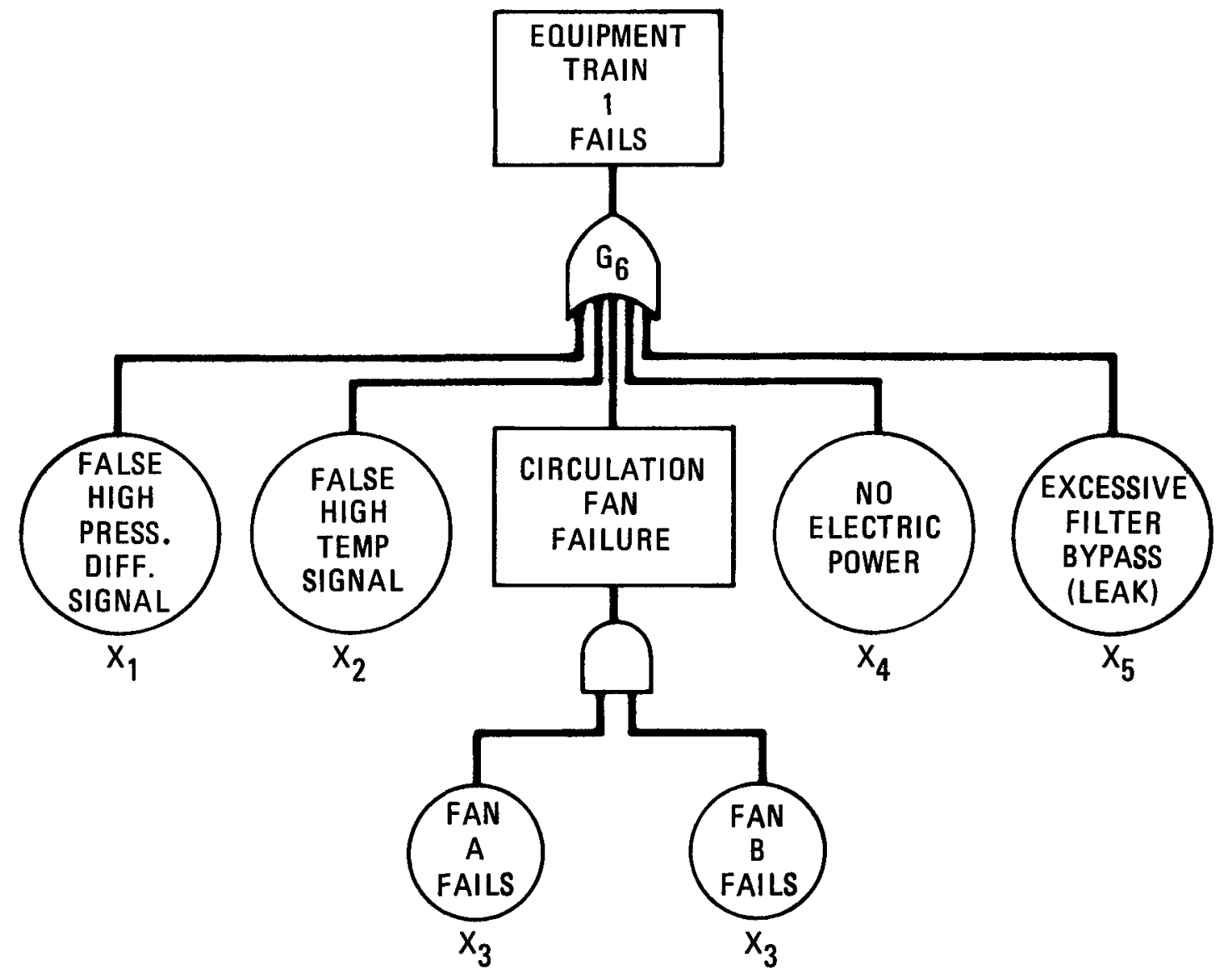

Fig. 5. Fault tree for equipment train for recirculation cleanup system 
In many cases, common mode failures of similar equipment in redundant systems are sufficiently important to safety that they must be modeled in the fault trees. Some types of common mode failure of a redundant system are treated explicitly in the fault trees, such as in Fig. 5. In that figure, it is seen that lack of electric power or presence of false signals regarding pressure differential and temperature can cause the train to fail, and this is because those events cause both fans to be shut down. In other cases where common mode failure data are available for the system or where the significant common failure modes are more difficult to know in adequate detail, another technique of common mode analysis known as the Beta-factor method is employed. The factor Beta is the ratio between the common mode failure rate of all similar redundant components in a system and the total failure rate for a single one of those components in the system.

The uncertainty in the predicted sequence frequency must also be known. The uncertainties are sometimes calculated by utilizing lognormal uncertainty functions in multiplicative operations such as in Eq. 1. However, in situations where a more accurate result is desired or where the lognormal or multiplicative assumptions are inadequate, a Monte Carlo method is used to obtain the probability density function which describes the uncertainty in the sequence frequency. One starts with the logical equations describing fault trees and proceeds to the logical equations describing event tree sequences. The uncertainty distributions of the values of the parameters of the fault tree are first utilized in the Monte Carlo process to generate an uncertainty distribution for each branch point probability. These are then combined by the Monte Carlo process to yield the uncertainty distribution for the sequence frequency. This resulting distribution allows the determination of the mean value of the sequence frequency as well as the median value. More complete descriptions of analysis of fault trees, common mode failures, and uncertainties are given in Volume II of Ref. 2, Sections $4.2,4.3$, and 4.7 , respectively. 


\subsubsection{Sequence Consequence Quantification}

The quantification of the consequences of a sequence, seen in Fig. 3, involves the prediction of consequences such as radiological dose for each branch of the event tree where radiation is released to the environment. This involves transient analyses that describe the condition of the plant as a function of time, such as temperature, pressures, and fluid flows which are needed to calculate radionuclide transport within the plant. The calculation of radionuclide transport starts with the release of any radionuclides through their primary barriers and then proceeds to follow the motion, plateout, filtration, and decay of these radionuclides during the course of the accident. Meteorology models are used to predict the dose to the public from any radioactivity which escapes the plant. The consequence analysis of course also requires knowledge of plant design and operator actions as well as design modifications for safety where appropriate.

The consequence analysis is based upon realistic modeling insofar as possible. It is important to know how small as well as how great a risk may be and it is also important to be able to clearly trace the dominant factors that actually cause either a low consequence or a high consequence.

Uncertainties in consequence predictions are also calculated. The principal technique for accomplishing this is to use the calculations of the physical phenomena, customarily done with large computer codes, as a source of information to determine which physical phenomena are of greatest importance in governing the transport of radionuclides. A simplified model of the transient phenomena based upon this knowledge is then created which is normalized to the more complete models, and a solution is obtained analytically. The equations of these solutions contain the dominant physical parameters of interest, the values of which can be described with uncertainty distributions. The equations and the uncertainty distribution of the parameters are input to a Monte Carlo process which generates uncertainty distributions on the outputs, which are the consequences. These uncertainty 
distributions can then yield both the mean and the median values of consequences. A more complete description of this process is given in Section 4.4.3 of Ref. 1 .

\subsubsection{Presentation of Results}

The presentation of results, indicated on Fig. 3, is of some importance because very many accident sequences are customarily studied. One of the principal methods of presenting the more important results in the past has been to plot the values of frequency and consequence for a given sequence on a plot of frequency versus consequence (F/C plot), such as Fig. 2 . Points lying to the upper right of the plot are customarily of greatest importance.

The information provided by this probabilistic risk assessment can be utilized, as seen on Fig. 3, as input in the selection of candidates for design basis accidents for safety analysis reports. However, one important factor is still lacking: a criterion for segregating the potentially large number of accident sequences into those that should be considered as candidates for DBAs and those that should be excluded. This criterion is developed in Section 4.

\subsection{PRA AS A SUPPLEMENTARY PROCEDURE}

Design basis accidents for Chapter 15 of SARs have been chosen in the past with deterministic techniques. Now, the use of probabilistic risk assessment should improve knowledge of the relations of accident sequences to one another and their relative importance, and will assist in making the study of reactor safety more systematic. This should improve the licensing process in the long term and lead to safer plant designs while minimizing effort wasted on insignificant analyses and costs of design features that do not contribute significantly to overall safety. 
The use of PRA in this way will also facilitate a growing understanding of where data bases need to be improved and where new statistical analyses need to be applied. During the use of PRA, the potentially large uncertainties must be accounted for; this applies also to overall risk assessment results from other studies which may be used for comparison.

At this time, PRA will not be accepted as the only basis for selection of design basis accidents. However, DBA selection is especially amenable to risk assessment for generic issues in the evaluation of new designs such as the HTGR, and PRA can provide valuable information to supplement the conventional procedure.

\subsection{PRA HISTORICAL BACKGROUND}

Probabilistic assessments, especially for reliability, have been used for some time by various industries and the regulatory agencies. A significant advancement in the concept of safety risk assessment in nuclear power plants was made by R. Farmer of the UKAEA (Ref. 3). He proposed an acceptance criterion for nuclear accidents in which the functions of interest are the frequency of the accidents and the consequences of the accidents, in this case the release of radioactive iodine. The importance of these coordinates has been confirmed by their subsequent use by other groups.

The expansion and integration of the various probability theory capabilities were accomplished on the greatest scale in the Reactor Safety Study (RSS) (Ref. 4). This study was a substantial advance over previous attempts to estimate the risks of nuclear power plants, not only because it made the study of reactor safety more rational, but also because it delineated a collection of procedures through which quantitative estimates of the risk could be derived. Some of its reviewers (Ref. 5) are certain that the error bands are understated but believe that it is nevertheless the most complete single picture of accident probabilities. 
A risk assessment study for the high-temperature gas-cooled reactor has been under way in the United States. It is the Accident Initiation and Progression Analysis study, in which selected accidents of both Class 9 and lower classes were examined and reported on in Ref. 1. This report was preceded by reports (Ref. 2) which screened a large number of events to estimate their importance. The earlier work was aimed toward providing information for the guidance of safety research and development, and it has been used this way during the past few years. The methodology of this work has many major similarities to that of the RSS but differs from it in some ways, especially in the treatment of common mode failures and of uncertainties on the consequences of accidents.

Probability analyses have also been used over the years in nuclear power plant programs in the Federal Republic of Germany (Ref.6). Recent emphasis has been to understand better the complex responses of equipment to accidents and then to make selective changes in design and operation which have a relatively large effect on the reliability of the equipment during an accident. A probabilistic risk assessment of a German pressurized water reactor is presently being directed by GRS* (Ref. 7).

KFA** of the Federal Republic of Germany also has a study under way on the probabilistic risk assessment of high-temperature gas-cooled reactors (Ref. 8). In the first portion of this study, the AIPA study was reviewed. The KFA review comments and the resolution of these were published in Refs. 8 and 1 , respectively. The German study is continuing, with the participation of GRS, to apply the methodology to German site conditions and German high-temperature reactor designs.

\footnotetext{
*Gesellshaft für Reaktorsicherheit **Kernforschungsanlage Jülich
} 
A probabilistic risk assessment was also performed for the Clinch River Breeder Reactor Plant (CRBRP) (Ref. 9). The safety situation with this plant was somewhat different from that of the other typical plants described above in that the CRBRP was specifically required to be designed such that potential consequences greater than the 10CFR100 guidelines have a frequency of no more than $10^{-6} /$ reactor-year (Ref. 10). The common mode failure analysis in this study was done somewhat differently from those in the RSS and the AIPA study. Safety work in this field is apparently inactive now, but if the CRBR review is reactivated, it is hoped that this frequency limit will be reconsidered on the basis of the policy statement by the NRC Commissioners on the Lewis Risk Assessment Review Group report (Ref. 5).

\subsection{NRC APPLICATIONS OF PRA}

The use of probabilistic risk assessment by the NRC is characterized by the actions of the NRC Commissioners in response to the Risk Assessment Review Group report on the Reactor Safety Study. The Commissioners support further use of PRA in nuclear regulations, as indicated in their policy statement (Ref. 12) which states, "taking due account of the reservations expressed in the Review Group Report and its presentation to the Commission, the Commission supports the extended use of probabilistic risk assessment in regulatory decision making." The Commissioners state in Ref. 13 that "the Staff shall give special attention to those activities ... especially amenable to risk assessment, i.e., dealing with generic safety issues, ... evaluating new designs."

One of the activities by the NRC Staff that has used risk assessments from the RSS is the study of anticipated transients without scram (ATWS). Volume 3 of NUREG-0460 (Ref. 14) was published in December 1978 and contains reactions to the findings of the Risk Assessment Review Group. It is found that engineering judgment is used extensively in this ATWS report, but that the Staff is also providing supplementary information from probabilistic studies. 
The report of the staff of the Three Mile Island Special Inquiry (Rogovin) Group (Ref. 15) recognizes that the past licensing approach should now be strengthened by taking advantage of the "significant advances in quantitative risk analysis." The Group expressed the opinion that "engineering judgment" cannot be eliminated, but that the use of risk assessment techniques will "put the judgments into the safety review process at a better point, judging which accident sequences are important, and why."

The proposal in this LTR is believed to be compatible with current actions in the NRC on the use of PRA and with recommendations for the use of PRA such as that made by the Rogovin Group. 


\section{INTERPRETIVE TECHNIQUE FOR SELECTION OF DBA CANDIDATES}

\subsection{OVERVIEW}

Design basis accidents are a special group of events that are analyzed in Chapter 15 of Safety Analysis Reports. This group of events contains cases that form the design basis for equipment that limits the doses predicted for accidents, and the chapter also includes cases to demonstrate the consideration of a wide spectrum of accident phenomena in the power plant. Many events are not included because they are less important as dose contributors than the limiting cases that are given. Other events are not included in Chapter 15 because they are too unlikely to be worthy of consideration as design basis events (though they may be considered in other ways). For example, core melt accidents in LWRs or core heatup accidents in HTGRs are considered to be sufficiently unlikely that they need not be included in Chapter 15 of SARs.

Probabilistic risk assessment, as discussed in Section 3.1, deals explicitly with consequences of radioactive releases and the likelihood of these releases. It therefore deals in a scientific way with two of the main parameters that have been used in the past to require the inclusion of events in a list of design basis accidents.

The technical development of the ideas for this methodology is presented with more clarity by using a graphical approach. Displays such as Fig. 6 can be made on which the likelihood (probability per unit time, or frequency) is plotted on the ordinate and the consequences (such as radiation dose) are plotted on the abscissa. Accidents with very low frequencies that fall on the lower portion of the plot are not suitable candidates for DBAs because they are considered too unlikely. Those events 


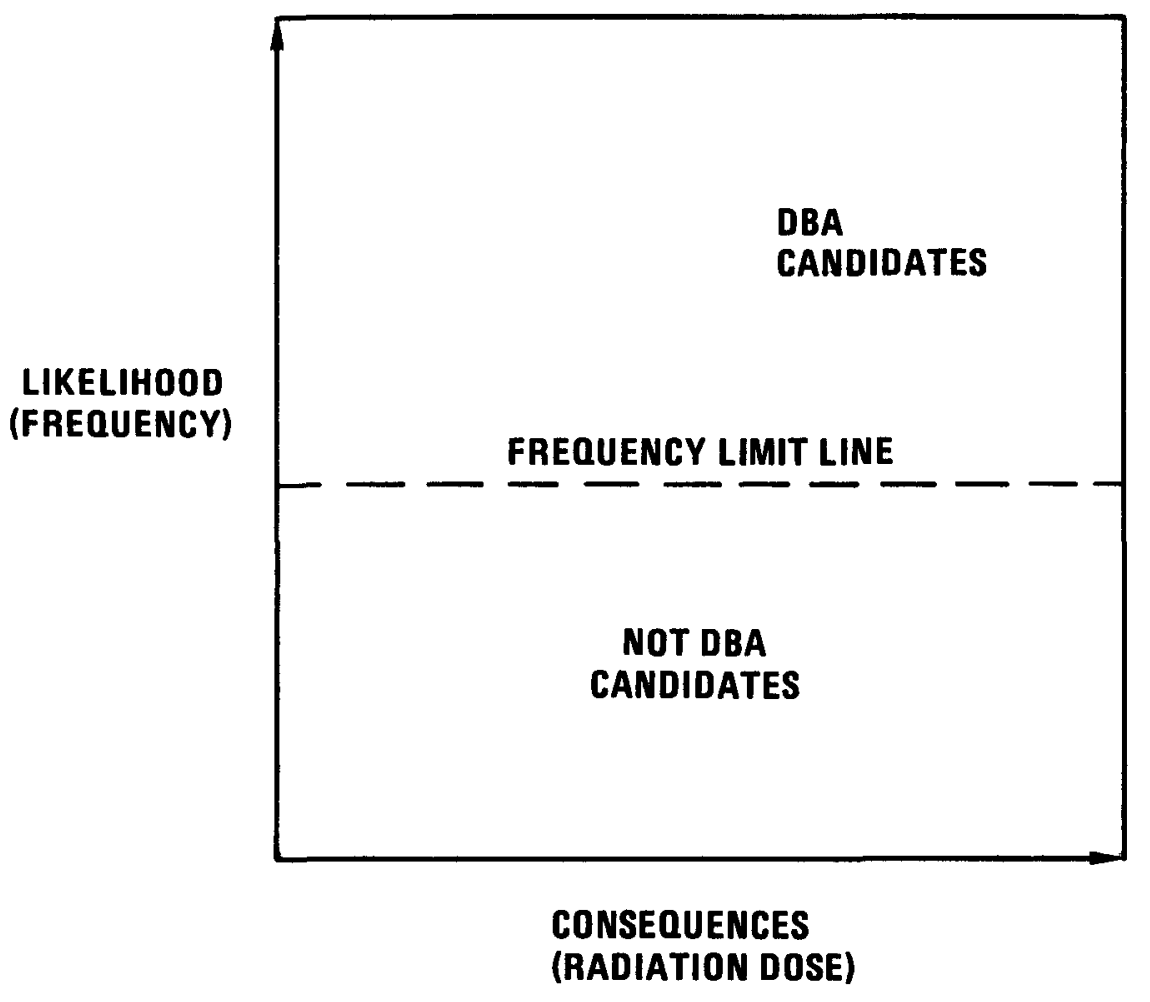

Fig. 6. Graphical display of interpretive technique 
of higher frequency falling on the upper portion of the plot are the events which are candidates to be DBAs. These relationships on the graph can be characterized by saying the plot is divided into two regions where the dividing line segregates the events into those to be considered as candidates for DBAs and those whose frequency of occurrence is sufficiently low that they can be excluded. Also, those higher frequency accidents giving higher doses are given stronger consideration to be DBAs than accidents with lower doses. This is in accord with the practice of choosing limiting cases that give the highest doses of interest.

The basic method of using PRA in selecting DBA candidates is therefore to calculate the frequencies and consequences for accident sequences of interest and to examine them, such as by means of a graph, to see in which region they lie. Because of uncertainties, the predicted values for frequency and consequence of a specific accident are given as probability density functions. A choice must be made of what values from the distributions will be chosen to be used in this interpretive technique and plotted. This problem is solved in Appendix A where derivations are presented of equations that yield single, "average" numbers for frequency and consequence, incorporating the effects of the uncertainties. The formula for the "average" frequency (Eq. 18 in Appendix A) turns out to be the mean. The equation for the "average" consequence (Eq. 29) is more complicated but similar to a mean. Some representative numerical values associated with the mean frequency are derived in Appendix $B$ to show the effect of uncertainty factors on the mean, since medians are quoted in much of the PRA 1iterature.

\subsection{FREQUENCY LIMIT LINE}

The dividing line between the graphical region where design basis accident candidates are plotted and the lower region where the sequences plotted are too unlikely to be DBA candidates is defined as the frequency limit line. The numerical value of this frequency could not be provided in the early years of nuclear power plant regulation because of inadequate 
development of the field of probabilistic risk assessment coupled with a lack of experience as to practicably achievable goals. In recent years, however, values for such a frequency have entered the regulatory process in some cases, and the capabilities for computing such frequencies and their uncertainties are improving.

A frequency of $10^{-6} /$ reactor-year has received widespread consideration as a future or ideal safety goal. The U.S. Atomic Energy Commission used this number in 1973 in a report on anticipated transients without scram (ATWS) (WASH-1270, Ref. 16) but did not examine whether it was practicable or reasonable compared to other risks. The details of the definition of that frequency evolved over the years until in April 1978, in report NUREG-0460, Volume 1 (Ref. 17), the frequency of $10^{-6} /$ reactor-year was the goal for the requirement that ATWS not cause core melting or doses greater than 10CFR100 (Ref. 18) values. In December 1978, in Volume 3 of NUREG0460 (Ref. 14), the frequency goal for ATWS was withdrawn. This action facilitates a fresh look at what has been achieved in the licensing of nuclear power plants to date and how that insight influences practicable and reasonable goals.

Probabilistic risk assessments of some reactors have been made which can give some insight into practicable goals. Two that are important to consider here are the Reactor Safety Study and the HTGR AIPA study. In these reports, the estimate for the median frequency for core melt in LWRs is $5 \times 10^{-5} /$ reactor-year and for core heatup in HTGRs is $3 \times 10^{-5}$. The uncertainty factors for these estimates (the number by which the median frequency is multiplied to obtain the upper bound frequency at the 95th percentile) are about 5 and 6 , respectively. The estimate of the mean core melt frequency for LWRs is $8 \times 10^{-5}$ based on the uncertainty factor of 5, as can be estimated using the techniques of Appendix B. The Risk Assessment Review Group concluded that the RSS uncertainties are greatly understated. If the uncertainty factor were doubled to 10 , the estimate of the mean core melt frequency would become $13 \times 10^{-5} /$ reactor-year. The RSS provides an assessment for actual plants, and the resulting frequencies 
are therefore one measure of what is practicable. Since the plants studied were also successfully licensed, the safety they have achieved is one measure of safety that is reasonable, although the impact of the Three Mile Island (TMI) accident will be discussed below.

An analysis by Apostolakis and Mosleh (Ref. 19) is of interest because of the uncertainties associated with the RSS results. Their work includes consideration not only of the RSS but also of (1) an examination of the experience with commercial LWRs in the U.S. up to about 1978 and (2) the opinions of several assessors about the methods and results of the RSS. The information is utilized in a formal procedure, based on Bayes' theorem, which modifies the frequencies while preserving coherence. The resultant mean frequency for core melt is $1.7 \times 10^{-4} /$ reactor-year.

Up to this point, this discussion suggests that the mean frequency of core melt in LWRs should be slightly less than $2 \times 10^{-4} /$ reactor-year. However, the risk assessments described above were made prior to the accident at TMI. An examination of the TMI accident and the Reactor Safety Study shows that the TMI type event was included in the RSS but raises the question whether some probability values used in the RSS are not being achieved in service, such as the unavailability of the auxiliary feedwater valves including common mode failures. This could lead to predictions of mean core melt frequencies higher than $2 \times 10^{-4}$. However, the high accident frequencies implied by TMI are not considered acceptable in the United States. Because of this, many improvements in safety are now being made in the power plants, such as the higher availability of the auxiliary feedwater system. These improvements are in the direction to restore the former confidence that the frequency for severe accidents is 1ow. Therefore, the accident frequency predictions which previously appeared to be both acceptable and achievable are believed to be suitable goals.

The mean frequency 1 imit selected is therefore $2 \times 10^{-4} /$ reactor-year. This value is selected because it represents an estimate of what the current licensing process can achieve in the avoidance of core melt. Design basis 
events should have a frequency greater than that of a core melt in recognition of the fact that core melt is not a design basis accident in today's licensing process. However, an essentially equal frequency has been selected to be conservative while not penalizing economic costs by even lower limit lines when the core melt sequences would still dominate the risk in this frequency range. The number includes a first-order accounting of the frequency uncertainty estimates. It is recognized that in years to come, if the core melt accident is treated by the NRC in significantly different ways, the frequency limit should appropriately change to match such an evolution. Further developments might also allow interpretation in terms of confidence level to be related to quantitative safety goals.

\subsection{EVENTS ABOVE THE FREQUENCY LIMIT LINE}

Those families of accident sequences or individual accident sequences that have mean frequencies above the frequency limit line are candidates to become design basis accidents. If they are subsequently chosen to be DBAs, their descriptions are placed in Chapter 15 of the SAR and they come under the usual requirements for limitations on dose to the public during an accident.

The families of accidents to be considered are those that have been identified in Chapter 15 of SARs for the HTGR, those identified in the Interim Safety Evaluation Report on GASSAR* (Ref. 20), and those that may be new or unique to a particular HTGR plant. This is a first step in establishing suitable coverage of possible accidents which is based on the current licensing approach to completeness. As the probabilistic risk assessment technology develops, it is anticipated that techniques will be developed to further increase the assurance of completeness in the examination of families of events.

*General Atomic Standard Safety Analysis Report 
A definition of the sequence frequency to be used in the selection process is needed. For example, definitions considered for other purposes in the past have been the median estimate, the best estimate, the expected value, and the upper bound. However, there are two aspects of this sequence frequency that properly determine what its definition should be. The first aspect is that the definition should be the same as that of the frequency limit to which it will be compared. This was developed in Section 4.2 and is the mean frequency for which the formalism is developed in Appendix A. The second aspect is that the calculated frequencies will be useful in considering what maximum radiation doses should be chosen for the accident as the proper licensing requirement. In this case, a fundamentally sound outlook is to ask whether the accident is likely to occur approximately each year in a single plant, or whether the accident is likely to occur less often than that but probably once in the lifetime of a single plant, or whether the accident is not expected to occur in a given single plant but is likely to occur somewhere in one of the plants in the nation. These questions can be answered using the formalism given in Appendix A which yields the mean frequency to account for uncertainties. The useful definition of sequence frequency is therefore the mean frequency for this second aspect also, and the chosen definition of frequency therefore remains the mean frequency.

Within current knowledge it is possible that some significant accident sequences may include multiple failures and/or common mode failures. It is believed that consideration of such failures needs to be a part of the selection process in order to move toward the treatment of safety issues in a well-balanced fashion. Common mode considerations are included in both the processes described in this LTR and in the AIPA studies which display the methodology for the calculation of sequence frequencies.

In approaching the definition of consequences for use in the DBA candidate selection process, it is necessary to account for uncertainties in both consequence and frequency. A probability density function for the consequences of a sequence would show the predicted range of consequences and 
the likelihood of the various consequences in that range. For the likelihoods to be meaningful, the predictions must be based on realistic models of phenomena and uncertainties. The formula for the density function is given in Appendix A for the general case where the uncertainty in frequency can affect the result. In comparing one sequence with another, it is desirable to compare single values of consequence. The uncertainties shown in the probability density function need to be interpreted to yield a single "average" consequence. A suitable method can be found by noting that the mathematical definition of risk is frequency times consequence. An expression for "average" consequence can be found such that the product of "average" frequency and "average" consequence yields the same risk as would be obtained by integrating over the uncertainty function on the plot of frequency and consequence. This expression for "average" consequence is derived as Eq. 29 in Appendix A. The basic definition of consequences is, therefore, the "average" consequence described above. Of course, if a sequence is seen to make a negligible contribution to the risk envelope at the upper right of a frequency-consequence plot, it is not necessary to provide a complete analysis.

On a frequency-consequence plot for a given plant concept, one can examine the points representing the sequences to determine which sequences significantly contribute to the risk envelope and which do not. An accident sequence may be a significant contributor because its predicted consequence is high even though the uncertainty is low. On the other hand, another accident sequence having similar frequency may contribute as much because its uncertainty is large even though the median consequence is smaller. (A change in design of the plant can also, in some cases, influence which accident sequences are significant contributors to the risk envelope.)

The graphical format which displays the interpretive technique, introduced in Fig. 6, can now be more fully detailed, as in Fig. 2. The 1ikelihood of an event becomes the accident frequency with units of (reactoryear) ${ }^{-1}$ and with uncertainty being accounted for by using the mean frequency. The consequences become radiation dose in rem where the uncertainties are 
accounted for by a special equation for a kind of mean as given by Eq. 29 in Appendix A. The accidents or accident families would be plotted as points, such as accidents A, B, and C. In this illustration, accidents $A$ and $C$ could be candidates for DBAs in distinction to $B$. Accidents below the limit line are not to be considered as candidates, and so the bottom of the graph may be the frequency limit 1 ine.

\subsection{EVENTS BELOW THE FREQUENCY LIMIT LINE}

The process of selection of sequences of events that should be considered as design basis accidents of necessity must include consideration of other sequences that are of interest from a radiological safety viewpoint but are of too low an estimated frequency of occurrence to be considered as design basis accidents. The existence of such sequences may be documented as part of the results of a comprehensive risk assessment, such as the AIPA study (Ref. 1) or the RSS. They would not be included in Chapter 15 of a Safety Analysis Report as they are not considered to be within the design basis of the plant, but they could be discussed in an appendix to Chapter 15 .

The comprehensive risk assessment provides the insights that need not be considered as to safety margins beyond the design basis. The methods for treating events beyond design basis are not within the scope of this report. However, continuing work on quantitative safety goals as a follow-on to this work will provide suggestions in this portion of the frequency spectrum. 


\section{EVALUATION OF DBA CANDIDATES}

The process of selecting the DBAs for Chapter 15 of the SARs wi11 rely on the traditional process. The knowledge about designs and accidents developed in the past will still be utilized, and the results from PRAs and their interpretations will supplement this knowledge. Therefore, three major portions of the effort are identifiable, as set forth below.

\subsection{HISTORICAL PERSPECTIVE}

Safety Analysis Reports have been written in the past for the HTGR. The DBAs in those reports of course received major consideration. There were often many reasons for inclusion of those events, including the characteristics of the power plant design, the categories of events that might lead to a release of radioactivity, and insights regarding accidents from other programs and other reactor types. These events will be given appropriate consideration in the PRA analyses.

In some cases, categories of events do not lead to significant accidents or individual accidents do not lead to significant consequences. However, care must be taken to determine whether these accidents or categories of accidents are worthwhile because they lead to design requirements which, in turn, result in the prevention of significant accidents because systems and components are correctly designed.

\subsection{PRA INTERPRETATIONS}

The techniques of interpreting the PRA results, as set forth in this LTR, yield candidates for design basis accidents. The reasons that these accidents are candidates can be found by tracing back through the analyses. 
The PRA analyses will also, in many cases, show the relations of various events to one another, which can be an aid in determining which event is the most important from the point of view of a safety design requirement. Such relationships may also show where some design requirements are not important. It is the intention to study the more significant events with PRA so that the effort can be placed where it will be most effective. This will generally mean that events involving multiple and common cause failures will be examined, rather than the traditional initiating event plus single failures.

Knowledge of accidents which have happened in the past is a part of understanding nuclear safety. This knowledge provides insights and crosschecks regarding previous predictions. The accidents that have occurred are a part of the data base used to generate the PRA results.

\subsection{APPLICATION TO CHAPTER 15 OF SARS}

When a set of design basis accidents is selected, a number of guidelines will be observed. The inclusiveness of the range of accidents will be considered. In previous SARs coverage of the possible range of accidents was accomplished by including a wide range of phenomena and comparing the events against similar events in other SARs.

There are also guidelines that assist in allowing a proper level of effort to be maintained in the design and licensing process. Accidents will be removed from the list when they only provide a repetition of previously established requirements. Dominant accidents will be retained in a given category; those accidents having lower risk in that category will be omitted from the list if they are not otherwise needed. Considerations of uncertainty will be present as appropriate in all these deliberations.

After the DBAs have been selected for Chapter 15, the deterministic calculations provided for inclusion in Chapter 15 could be done by the 
customary licensing methods. This means that they may be conservative and may use previous conservatism precedents in most cases until or unless the advancements of technical knowledge provide bases for eliminating conservatism. Those events that have frequencies near but just above the frequency limit line and which have the highest doses must have dose consequences that do not exceed the guidelines of 10CFR100. The use of 10CFR100 guidelines for the most limiting accidents analyzed in Chapter 15 accords with current practice. This LTR does not include development of a position on suitable dose criteria for higher frequency accidents for which a lower dose guideline would be appropriate. 
1. "HTGR Accident Initiation and Progression Analysis Status Report, Phase II Risk Assessment," DOE Report GA-A15000, General Atomic Company, April 1978.

2. "HTGR Accident Initiation and Progression Analysis Status Report," ERDA Report GA-A13617, v. I-VIII, General Atomic Company, October 1975 to January 1977.

3. Farmer, F.R., "Siting Criteria - A New Approach," in Proceedings, IAEA Symposium on Containment and Siting of Nuclear Power Plants, April 3-7, 1967 (paper SM-89/34), pp. 303-329.

4. "The Reactor Safety Study - An Assessment of Accident Risks in U.S. Commercial Nuclear Power P1ants," USAEC Report WASH-1400, October 1975.

5. Lewis, H.W., et a1. "Risk Assessment Review Group Report to the U.S. Nuclear Regulatory Commission," NRC Report NUREG/CR-0400, September 1978.

6. Bast1, W., H. Hoertner, and P. Kafka, "Influence of Probabilistic Safety Analysis on Design and Operation of PWR Plants," in Proceedings, Topical Meeting on Probabilistic Analysis of Nuclear Reactor Safety, May 8-10, 1978 (paper II.1, Vo1. 1), pp. II.1-1 to II.1-20.

7. Birkhofer, A., "Stand der Deutschen Risikostudie für Druckwasserreaktoren Sammlung der Vorträge zum Jahreskolloquium 1977 zum Projekt 'Nukleare Sicherheit'," KFK 2570, Dezember 1977, Kernforschungszentrum Karlsruhe.

8. Doehler, J., et al. "AIPA Methodology Reviewed, Improved and Applied to German HTGRs," in Proceedings, Topical Meeting on Probabilistic Analysis of Nuclear Reactor Safety, May 8-10, 1978 (paper V.5, Vo1.2), pp. V.5-1 to V.5-10.

9. "CRBRP Risk Assessment Report," CRBRP-1, March 1977. 
10. Letter from R.P. Denise, U.S. Nuclear Regulatory Commission, to L.W. Caffey, Clinch River Breeder Reactor Project Office, May 6, 1976.

11. Simpson, D.E., "LMFBR Accident Consequences Assessment," in Nuclear Systems Reliability Engineering and Risk Assessment, J.B. Fussell and G.R. Burdick (eds.), Society for Industrial and Applied Mathematics, Philadelphia, 1977, pp. 128-166.

12. "NRC Statement on Risk Assessment and the Reactor Safety Study Report (WASH-1400) in Light of the Risk Assessment Review Group Report," U.S. Nuclear Regulatory Commission, January 18, 1979.

13. Memo from Samuel J. Chilk to Lee V. Gossick, "Staff Actions Regarding Risk Assessment Review Group Report," U.S. Nuclear Regulatory Commission, January 18, 1979.

14. "Anticipated Transients Without Scram for Light Water Reactors," U.S. Nuclear Regulatory Commission Report NUREG-0460, Vol. 3, December 1978.

15. "Three Mile Island: A Report to the Commissioners and to the Public," Vo1. 1, Nuclear Regulatory Commission Special Inquiry Group, Mitche11 Rogovin, Director.

16. "Anticipated Transients Without Scram for Water-Cooled Power Reactors," USAEC Report WASH-1270, September 1973.

17. "Anticipated Transients Without Scram for Light Water Reactors," USNRC Report NUREG-0460, Vo1. 1, April 1978.

18. United States Nuclear Regulatory Commission Rules and Regulations, Title 10-Atomic Energy, Part 100, Reactor Site Criteria.

19. Apostolakis, G., and A. Mosleh, "A Study on the Qualification of Judgment," in Proceedings, Topical Meeting on Probabilistic Analysis of Nuclear Reactor Safety, May 8-10, 1978 (paper VI.5, Vo1. 2), pp. VI. 5-1 to VI.5-11.

20. "GASSAR-6, General Atomic Standard Safety Analysis Report," February 5, 1975 (NRC Docket STN 50-535). 


\begin{abstract}
APPENDIX A
DERIVATION OF CHARACTERISTIC FREQUENCY AND

CONSEQUENCES WHICH ACCOUNT FOR UNCERTAINTIES
\end{abstract}

CHARACTERISTIC FREQUENCY

When frequencies are estimated in probabilistic risk assessment, uncertainties in the frequency can also be estimated. A probability density function for the estimated frequency can hence be derived. Appropriate functions for accident frequencies typically require at least two parameters for an adequate description, and ideally could even require a table of values.

The problem is to characterize such a function in a simpler way to facilitate communication, comprehension of results, and decision making. A single characteristic frequency for each accident sequence would be best.

The characteristic of the distribution which has been used most often in the past has been the median. The median is the value for which the confidence is $50 \%$ that the true value of frequency for the specified event is greater than the median, and $50 \%$ that the true value is less. The value of the median tells nothing about the spread of the distribution the degree of uncertainty. And so, although one knows the confidence of the median is $50 \%$, one cannot know how much greater the frequency may be just by knowing the median.

One way to alleviate part of this problem is to chose a different point on the distribution having a confidence higher than $50 \%$ that the true frequency is not greater than the chosen point, for example, a point with $70 \%$ confidence. The quotation of this frequency point again tells 
one nothing about how much greater the frequency may be; it just tells one that the true frequency is less likely to be greater.

To proceed further with this problem, some broadening of the issue is necessary to consider more deeply the reason for choosing a characteristic frequency. When one is interested in events with quite low frequencies, such as predicted events that have not been experienced, a legitimate question can be raised as to what the objective criterion for the definition of these low numbers is. It is suggested here that the criterion should be that there be a reasonably direct connection between these quoted frequencies and public safety. Public safety is fundamentally concerned with whether an accident will probably happen (as well as with the consequences).

The connection between public safety and quoted accident frequencies is that the frequencies, in events per reactor-year, can be related to the probability that the events will happen (or even the number of times that they are expected to happen) in some given number of years among some given reactors. A suitable equation giving this relation is:

$$
\begin{aligned}
\text { Probability }= & 1-\exp [-(\text { characteristic frequency) } \\
& \text { (no. of reactors) (no. of yrs.) }]
\end{aligned}
$$

However, it is not customary to present such probabilities themselves. In order to maintain continuity with previous experience, a characteristic single frequency, an "average" frequency, is needed which is related in the simple way given above to such a probability and includes the effect of uncertainties on the probability.

This Appendix answers the question: What is the mathematical expression for that characteristic frequency, which is to say, what is the derivation of the equation which shows which kind of "average" should be taken? 
The solution to be developed below will involve an integral of the entire uncertainty distribution, and thereby overcomes the problems described above for characteristic frequencies chosen as single points, based on a given value of confidence, from a distribution. The solution might be interpreted in terms of some confidence level (an approach under consideration by some people) but further development would be required to determine how that approach relates to quantitative safety.

The underlying logic leading to the equation starts with hypothesizing an experiment in which many reactors are operated for very many years.

One could choose a specific accident sequence and watch for these events in the experiment. As they happen, one could record the time at which the event occurs and the consequences. One could then choose sequential time intervals and calculate accident rates and associated consequence density functions for each interval and, hence, for the reactor population. Each accident rate $F$ and its associated consequence probability density function are associated with a certain proportion of the population of reactors. These results could be expressed as a joint probability density function, $\phi(F, C)$.

With such a function, $\phi(F, C)$, the probability of having an accident of the given sequence in the range of rates between $F_{a}$ and $F_{b}$ and in the range of consequences between $C_{d}$ and $C_{e}$ can be evaluated as

$$
\int_{F_{a}}^{F_{b}} \int_{C_{d}}^{C_{e}} \phi(F, C) d C d F .
$$

The density function $\phi$ that we would use in analysis would be derived by means of the detailed probability and consequence analysis for a plant.

The goal is to predict the probability that a certain sequence will occur in a collection of plants over a given time interval and within 
specified consequence limits. Individual plants will be assumed to have a constant accident rate $\mathrm{F}$ for a given accident sequence.

One plant in a set of plants having rate $F_{1}$ will have a probability of having no accident in time $\mathrm{T}_{1}$ of

$$
\mathrm{e}^{-\mathrm{F}_{1} \mathrm{~T}_{1}}
$$

Two plants would have a success probability of

$$
\left(e^{-F_{1} T_{1}}\right)\left(e^{-F_{1} T_{1}}\right),
$$

and the total of $n_{1}$ plants in the set would have a probability of

$$
\prod_{n_{1}} e^{-F_{1} T_{1}}=e^{-F_{1} n_{1} T_{1}}
$$

The probability of this set having a first accident is

$$
1-e^{-\mathrm{F}_{1} \mathrm{n}_{1} \mathrm{~T}_{1}}
$$

Another set with different rate, $F_{2}$, and a total number of plants $n_{2}$, would have a success probability in time $\mathrm{T}_{2}$ of

$$
\prod_{n_{2}} e^{-F_{2} 2_{2}}=e^{-F_{2} n_{2} T_{2}}
$$

The two sets together would then have a success probability of

$$
\left(e^{-\mathrm{F}_{1} \mathrm{n}_{1} \mathrm{~T}_{1}}\right)\left(e^{-\mathrm{F}_{2} \mathrm{n}_{2} \mathrm{~T}_{2}}\right)
$$


The number of reactor years per set, $n_{1} T_{1}$ and $n_{2} T_{2}$, may best be converted to a proportion of the total number of reactor years. If

$$
\mathrm{T}=\sum_{\mathrm{a} 11} \mathrm{n}_{i} \mathrm{~T}_{i},
$$

then the proportion of reactor years, $I_{i}$, having $F_{i}$ (in a specified range of consequence for the given sequence, $C_{d}$ to $C_{e}$ ) is

$$
I_{i}=\int_{C_{d}}^{C_{e}} \phi\left(F_{i}, C\right) d C \Delta F_{i}=\frac{n_{i} T_{i}}{T},
$$

where $F_{i}$ ranges from $(1 / 2)\left(F_{i-1}+F_{i}\right)$ to $(1 / 2)\left(F_{i}+F_{i+1}\right)$.

The change in the definition of $\phi$ to be for the "proportion of reactor years" is significant and must not be overlooked in applying the method.

The probability of having a first accident is then 1 minus the probability of no accident in all plants, or

$$
\begin{aligned}
P & =1-\left(e^{-F_{1} \mathrm{TI}_{1}}\right)\left(e^{-\mathrm{F}_{2} \mathrm{TI}_{2}}\right)(\quad) \ldots \\
& =1-\prod_{i} e^{-\mathrm{F}_{1} \mathrm{TI}_{i}} \\
& =1-\exp \left(\sum_{i}-\mathrm{F}_{i} \mathrm{TI}_{i}\right)
\end{aligned}
$$




$$
=1-\exp \left[\sum_{i}-\mathrm{F}_{i} \mathrm{~T} \int_{\mathrm{C}_{\mathrm{d}}}^{\mathrm{C}_{\mathrm{e}}} \phi\left(\mathrm{F}_{i}, \mathrm{C}\right) \mathrm{dC} \Delta \mathrm{F}_{i}\right]
$$

In the limit of a continuous function for $\phi$, the equation becomes

$$
P=1-\exp \left[\int_{\text {all F }} \int_{C_{d}}^{C_{e}}-\operatorname{FT} \phi(F, C) d C d F\right] \text {. }
$$

This is the basic equation.

The equation can be used to obtain a probability for consequences greater than $C_{d}$ by setting the $C_{e}$ limit to infinity. This is similar to a complementary cumulative distribution calculation.

An "average" accident rate can be defined and found for this cumulative case which yields the same probability of an accident by means of the following equation

$$
1-\exp \left(-F_{\text {ave }} T\right) \equiv P=1-\exp \left[\int_{\text {al1 }} \int_{F^{>C} C_{d}}-F T \phi(F, C) d C d F\right],
$$

which reduces to

$$
F_{\text {ave }}=\int_{\text {a11 } F} \int_{\geq C_{d}} F \phi(F, C) d C d F
$$


This is the equation that shows the kind of "average" to be taken. The equation is that for a mean of the distribution of $F$. This equation means that for purposes of assessing the probabilities of accidents for sequences that have large uncertainties in $F$, a properly averaged $F$ will emphasize the higher values of $F$ in the uncertainty range for probability distributions on $\mathrm{F}$ which are skewed as is a lognormal function. This technique presently yields a first-order accounting of uncertainties because the numerical values for uncertainty distributions that are input to the equations are not well known.

The equation yields a complementary cumulative function for $F$ ave as a function of $\mathrm{C}_{\mathrm{d}}$ as it is written. Such a function is usually used to describe the collection of all accidents for a plant. Note that $\phi$ must be developed to include correlations between sequence parameters which make up the collection.

When $C_{d}$ is set to zero, and $\phi$ is for an individual sequence or a family of sequences, $F_{\text {ave }}$ is the single characteristic frequency for the individual sequence or family, including the effect of uncertainties:

$$
F_{\text {ave }}=\int_{a 11 \text { F }} \int_{a 11 C} F \phi(F, C) \mathrm{dCdF} .
$$

All the values of $F$ ave for different sequences must be realistic so that comparing them to each other is meaningful. The uncertainties expressed in $\phi$ must therefore be as realistic as possible and must not be intentionally biased to be either conservative or optimistic. 
Characteristic Consequence

The characteristic frequency $F_{\text {ave }}$ developed above, is the value that would be plotted on a graph of frequency versus consequence. The equation for the single value of consequence which goes with this $F_{\text {ave }}$ is needed.

This problem can be approached in two parts. One, find the probability density function of consequence compatible with $\mathrm{F}_{\text {ave }}$. Two, determine what single value of consequence should be derived from the density function to provide an appropriate characteristic value for consequence, C ave, including the effect of uncertainties.

To introduce the probability density function, an experiment can again be hypothesized over very many reactor years. The resulting data that are of interest constitute a bar chart of the fraction of the total number of accidents observed as a function of consequence for the accident sequence (or family) of interest. Such a chart presents an estimate of the probability density function (pdf) on consequences. This function can be calculated using the concepts and symbols used above.

The probability of having a plant in a state or condition where its frequency of accidents is in $\mathrm{dF}$ about $\mathrm{F}$ and the resultant consequence is in $\mathrm{dC}$ about $\mathrm{C}$ is

$$
\mathrm{dP}(\mathrm{S})=\phi(\mathrm{F}, \mathrm{C}) \mathrm{dCdF}
$$

When the plant is in that state, the probability of an accident in time $\mathrm{dT}$ is

$$
\mathrm{DP}(\mathrm{A} \mid \mathrm{S})=\mathrm{FdT} \text {. }
$$


The probability of the plant having an accident characterized by having $\mathrm{F}$ in $\mathrm{dF}$ and $\mathrm{C}$ in $\mathrm{dC}$ is therefore

$$
\begin{aligned}
\mathrm{dP}(\mathrm{A} \text { at } \mathrm{F}, \mathrm{C}) & =\mathrm{dP}(\mathrm{S}) \quad \mathrm{dP}(\mathrm{A} \mid \mathrm{S}) \\
& =\mathrm{F} \phi(\mathrm{F}, \mathrm{C}) \mathrm{dCdFdT}
\end{aligned}
$$

To approach the pdf of $\mathrm{C}$, the function must be integrated over the values of $F$ for each value of $C$, yielding

$$
\cdot d P(A \text { at } C)=\int_{a 11 F} F \phi(F, C) d C d F d T
$$

It is sufficient for the purposes of the immediate analysis to deal with probability per unit time, which implies certain assumptions of constancy of functions in the application of the equations. The probability equation can then be written

$$
\frac{\mathrm{dP}}{\mathrm{dT}}=\left[\int_{\mathrm{a} 11 \mathrm{~F}} \mathrm{~F} \phi(\mathrm{F}, \mathrm{C}) \mathrm{dF}\right] \mathrm{dC}
$$

This is the probability per unit time of the plant having an accident with consequences in $\mathrm{dC}$ about $\mathrm{C}$. This is the functional form of the pdf of $\mathrm{C}$ but must have its integral normalized to one. Since

$$
\mathrm{F}_{\mathrm{av} \cdot \mathrm{I}}=\int_{\mathrm{a} 11 \mathrm{C}} \int_{\mathrm{a} 11 \mathrm{~F}} \mathrm{~F} \phi(\mathrm{F}, \mathrm{C}) \mathrm{dFdC},
$$


then

$$
\operatorname{pdf}(\mathrm{C})=\frac{1}{\mathrm{~F}_{\text {ave }}}\left[\int_{\mathrm{a} 11} \mathrm{~F} \phi(\mathrm{F}, \mathrm{C}) \mathrm{dF}\right] .
$$

It would be desirable if the single characteristic value of $\mathrm{C}$ were consistent with the concept of risk being the product of frequency and consequence as used in the RSS and AIPA studies. Considering the whole range of uncertainty, one can find the total risk for an accident sequence by summing the individual risks from incremental values of $\mathrm{F}$ and $\mathrm{C}$. Thus, the risk, $\mathrm{R}$, is

$$
R=\int_{\mathrm{a} 11 \mathrm{C}} \int_{\mathrm{a} 11 \mathrm{~F}} \mathrm{FC} \phi(\mathrm{F}, \mathrm{C}) \mathrm{dFdC}
$$

A choice of $\mathrm{C}_{\text {ave }}$ consistent with previous derivations of $F_{\text {ave }}$ would then satisfy

$$
\mathrm{R}=\mathrm{F}_{\text {ave }} \mathrm{C}_{\text {ave }} \text {. }
$$

$\mathrm{C}_{\text {ave }}$ is then defined to be

$$
C_{\text {ave }}=\frac{1}{F_{\text {ave }}} \int_{\text {all C }} \int_{\text {al1 } F} C F \phi(F, C) \mathrm{dFdC}
$$

When this is compared to $\operatorname{pdf}(C)$, it is seen that the derived $C$ ave happens to be the mean of the pdf of $C$ which includes the effects of correlation between $\mathrm{F}$ and $\mathrm{C}$ expressed in $\phi$. 
This value of $\mathrm{C}_{\text {ave }}$ can then be used with $\mathrm{F}_{\text {ave }}$ to plot sequences or families of sequences on a frequency-consequence graph and thereby include the effect of uncertainties. 


\section{APPENDIX B \\ DERIVATION OF REPRESENTATIVE NUMERICAL VALUES \\ ASSOCIATED WITH AVERAGE FREQUENCY}

The basic equation for the probability, $P$, of an event from Appendix $A$ is

$$
P=1-\exp \left[\int_{\mathrm{a} 11 \mathrm{~F}} \int_{C_{d}}^{C_{\mathrm{e}}^{\mathrm{e}}}-\operatorname{FT} \phi(F, C) \mathrm{dCdF}\right] \text {, }
$$

where $\mathrm{F}$ is the frequency, $\mathrm{C}$ is the consequence, $\mathrm{T}$ is the operating time in reactor years, and $\phi(\mathrm{F}, \mathrm{C})$ is the probability density function incorporating uncertainties on frequency and consequence.

A representative $\phi$ can be taken to be the product of two lognormal distributions,

$$
\phi=\mathrm{N}_{1}(\mathrm{~F}) \mathrm{N}_{2}(\mathrm{C})
$$

The range of $\mathrm{C}$ can be unrestricted; all consequences can be included. This results in

$$
\int_{C_{d}}^{\mathrm{C}} \operatorname{FTN}_{1}(F) N_{2}(C) d C=\operatorname{FTN}_{1}(F)
$$


The integral over $F$ can be conveniently handled by finding a factor $\rho$ which allows the integral to be replaced with a product:

$$
\rho=e^{0.18481 n^{2} f},
$$

where $f$ is the uncertainty factor (90\% interval) for $N_{1}(F)$, the number by which the median frequency is multiplied to obtain the upper bound frequency at the 95 th percentile. This gives

$$
\mathrm{F}_{\text {ave }}=\mathrm{F}_{\mathrm{m}} \rho \text {, }
$$

where $\mathrm{F}_{\mathrm{m}}$ is the median frequency of the event being studied. Then

$$
P=1-\exp \left(-F_{m} T \rho\right)
$$

The factor $\rho$ provides an easy accounting for the effect of the lognormal uncertainty distribution on the exponent above. Representative values are as follows:

\begin{tabular}{c|c|c|c|c|c|c|c|c}
$\mathrm{f}$ & 1 & 3 & 5 & 10 & 30 & 100 & 300 & 1000 \\
\hline$\rho$ & 1. & 1.25 & 1.61 & 2.66 & 8.48 & 50.4 & 408. & 6760.
\end{tabular}

If a best estimate of the number of events is desired, the expression is

$$
\mathrm{F}_{\mathrm{m}}^{\mathrm{T}} \mathrm{p}
$$

assuming that no changes to plant design are made after accidents so that the values of $F_{m}$ and $\rho$ are not functions of time. 